\title{
Medication adherence in chronic illness: do beliefs about medications play a role?
}

This article was published in the following Dove Press journal:

Patient Preference and Adherence

\author{
Jacinthe Lemay' \\ Mohammad Waheedi ${ }^{2}$ \\ Sarah Al-Sharqawi' \\ Tania Bayoud ${ }^{2}$ \\ 'Department of Pharmacology \\ and Therapeutics, ${ }^{2}$ Department \\ of Pharmacy Practice, Faculty \\ of Pharmacy, Kuwait University, \\ Safat, Kuwait
}

Correspondence: Jacinthe Lemay Department of Pharmacology and Therapeutics, Faculty of Pharmacy, Kuwait University, PO Box 24923,

Safat I3I I0, Kuwait

Tel +965 2463604 I

Fax +965 2463684 I

Email j.lemay@hsc.edu.kw
Background: Several medicines are prescribed for chronic disease management; however, adherence to long-term therapy remains poor. Culture influences beliefs about medications and, ultimately, adherence to treatment. There is a paucity of data with regard to beliefs about medications in the Middle East region, and it remains to be determined how these beliefs would impact treatment adherence.

Objectives: To investigate the relationship between patients' beliefs about medications with self-reported adherence to treatment among a chronically ill multicultural patient population.

Methods: A prospective cross-sectional study was conducted among patients treated for chronic illnesses in the Ministry of Health primary care clinics in Kuwait. Patients completed a questionnaire that consisted of questions to collect information about their health status and demographics using validated instruments: the Beliefs about Medication, Sensitive Soma Assessment Scale, and Medication Adherence Report Scale-5 items. The main outcome measures were self-reported adherence to medications, beliefs, and perceived sensitivity toward medications.

Results: Of the 1,150 questionnaires distributed, 783 were collected-giving a response rate of $68.1 \%$. Of the 783 patients, $56.7 \%$ were male, $73.7 \%$ were married, $53.3 \%$ were non-Kuwaitis, and $49.4 \%$ had low income $(<1,000 \mathrm{KD} / 3,350$ USD monthly). Patients self-reported having a cardiovascular illness $(80.2 \%)$, diabetes mellitus $(67.7 \%)$, respiratory disease $(24.3 \%)$, or mood disorder (28.6\%). Participants had a mean of two comorbid illnesses and indicated taking an average of four prescription medicines to treat them. A structural equation model analysis showed adherence to medications was negatively impacted by higher negative beliefs toward medications (beta $=-0.46$ ). Factors associated with negative beliefs toward medications included marital status (being unmarried; beta $=-0.14$ ), nationality (being Kuwaiti; beta $=0.15$ ), having lower education level (beta $=-0.14$ ), and higher illness severity (beta $=0.15$ ). Younger age (beta $=0.10)$ and higher illness severity $($ beta $=-0.9)$ were independently associated with lower medication adherence. Income and gender did not influence medication adherence or beliefs about medications. The combined effect of variables tested in the model explained $24 \%$ of the variance in medication adherence.

Conclusion: Medication adherence is a complex, multifaceted issue and patient beliefs about medications contribute significantly, although partially, to adherence among a multicultural Middle Eastern patient population.

Keywords: beliefs, medication adherence, Kuwait, primary care, structural equation model

\section{Introduction}

Medications are an essential part of chronic disease management. However, adherence to long-term therapy remains poor. ${ }^{1}$ The World Health Organization (WHO) defines adherence to long-term therapy as 'the extent to which a person's behavior - taking medication, following a diet, and/or executing lifestyle changes - corresponds with 
agreed recommendations from a health-care provider". ${ }^{1}$ Poor adherence is considered a major drug-related problem and is associated with increased emergency-room visits, hospitalizations, and suboptimal clinical outcomes, all of which are associated with an increased burden on the health care system. ${ }^{1,2}$ Reasons for poor treatment adherence include disease characteristics and severity, treatment factors (eg, treatment duration, number of medications, cost, frequency of administration), and medication side effects, among others. ${ }^{3}$ In addition, patients have their own beliefs and perceptions about medications, which can have a significant impact on their intention to take the prescribed medications. ${ }^{4}$

Data from Middle Eastern countries indicate that medication adherence ranges from $1.4 \%$ to $88 \%$ depending on the methods used to assess and quantify adherence. ${ }^{5}$ Recent data from diabetic patients in Kuwait showed that the factors that influence medication adherence include patient's knowledge about the disease, a large gap from therapeutic goals, as well as beliefs about medicines and diabetes, attitudes toward diabetes, perceptions of self-expertise with the disease, and social stigma, among others. ${ }^{6,7}$ Moreover, in patients with hypercholesterolemia, data showed that adherence to statins is higher with those suffering from multiple comorbid conditions. ${ }^{8}$ Furthermore, a study conducted in Kuwait assessing the influence of health beliefs on medication adherence among patients suffering from depression found that adherence to medication was better if patients had the intention of taking their medications or believed that depression was best treated with medication. ${ }^{9}$ Similar observations were also reported among patients in Kuwait suffering from schizophrenia and mania. ${ }^{10}$ Adherence to medication was found to be higher than adherence to lifestyle changes, ${ }^{7}$ and this observation may be associated with patients perceiving medications as necessary and more important to manage their illness, and adherence being associated with a higher perception of personal control over their illness. ${ }^{11,12}$ Furthermore, results from a meta-analysis study suggested that several components of the health belief model, such as illness severity and patient awareness of this severity, were significant predictors of adherence to treatment. ${ }^{13}$

Collectively, these data indicate that health and medication beliefs have a significant impact on patient adherence to treatment. Data showed that perceived concerns about the benefits of medications or beliefs that medications are overused or harmful negatively impacts adherence to treatment. ${ }^{12,14}$ Similarly among depressed patients, data showed that those who were concerned about the risk of addiction to their medicines were less adherent to their treatment. ${ }^{9}$ Despite the extensive body of literature examining the relevance of various beliefs across different ethnic groups, ${ }^{4,6-10,15-18}$ there is a paucity of data documenting the impact of specific beliefs about medicines on treatment adherence among chronically ill patients managed in primary-care settings in Kuwait. Therefore, this study proposes to expand and complement the existing body of data from Kuwait by assessing patient beliefs about their prescribed medication and understanding how those beliefs are associated with adherence to treatment.

\section{Methods}

\section{Study design and patient population}

This was a descriptive, cross-sectional study carried out from January to August 2016 among patients who were being followed up for the treatment of chronic diseases across 38 primary-care polyclinics within the five health regions (Capital, Al-Farwaniyah, Al-Ahmadi, Hawally, and Al-Jahra) in Kuwait. Patients aged 21 years and above who are were able to provide informed consent, who have been receiving treatment for a duration of at least 3 months, ${ }^{19}$ and who are were actively filling prescriptions for medications related to a chronic disease were eligible to participate. Only those participants who signed the informed consent were included. An ethical approval was obtained from the Standing Committee for Coordination of Health and Medical Research, Ministry of Health $(\mathrm{MOH})$, and the Health Science Center (HSC) Ethics Committee for Student Research before any study procedures were conducted.

\section{Study tool}

Patients were provided with a self-administered six-page questionnaire in English or Arabic. The first part of the questionnaire listed a series of introduction questions to collect information about the patient's self-reported health status, disease conditions, comorbidities, and number and types of medications being prescribed. Following these questions, there were three validated instruments: Beliefs about Medication-12 items (BMQ-12), Sensitive Soma Assessment Scale (SS-5), and Medication Adherence Report Scale-5 items (MARS-5), which are described further. The last part of the questionnaire was meant to collect demographic variables including age, gender, income, nationality, marital status, employment status, and educational level. The questionnaire consisted of statements that were pretested for reliability by other research groups. . $20-25^{2}$ To test the content and face validity of the questionnaire and the feasibility of data collection methods, a pilot study was conducted among 15 patients across 
three different polyclinics. Minor formatting changes and a few text modifications were made to improve the clarity of some questions and answer statements without changing their intended meaning. Patients completed the study questionnaire with assistance from a researcher. Researcher guidance was shown, in the pilot study, to improve respondents' comprehension and reduce the problem of missing values. Data obtained from the pilot study were excluded from the results of the reported study.

\section{Beliefs about Medicines Questionnaire and Sensitive Soma Assessment Scale}

The BMQ-12 assessed some of the key beliefs influencing adherence to prescribed medications and has been shown to be valid and reliable across a range of clinical conditions including asthma, diabetes, cardiovascular disease, kidney disease, psychiatric disease, and cancer., 4,23,26,27 The BMQ-General 12-item scale has been translated and validated in Arabic, making it an appropriate tool to use in the population of Kuwait. ${ }^{20}$ The BMQ-General 12-items scale was complemented with the SS-5 5-item scale, which has been frequently combined and correlated with treatment adherence. ${ }^{4,23,26}$ The SS-5 is a validated instrument that was developed to assess the perceived sensitivity of patients taking medications and was shown to have a strong association with adherence. ${ }^{21,23,28,29}$ Moreover, it has been translated and validated in Arabic. ${ }^{20}$ For both scales, patients indicated their degree of agreement with each individual statement about medicines on a five-point Likert scale, ranging from $1=$ strongly disagree to $5=$ strongly agree. Scores obtained for the individual items within each scale were added to give a scale score. Higher scores indicated stronger beliefs in the concepts represented by the scale (Overuse, Harm, or Benefit) and high perceived sensitivity to potential adverse effects of medication (SS-5).

\section{Medication Adherence Report Scale 5-item}

The MARS, originally proposed by Horne and Weinman, is a brief patient-reported measure of medication adherence that has demonstrated good psychometric properties. ${ }^{30}$ The MARS-5 instrument, a shorter version of the MARS, comprised five items designed to address nonadherent behavior. The first statement of the instrument evaluated unintentional nonadherence, whereas the other four statements assessed intentional nonadherence. The instrument was scored on a five-point Likert scale ranging from $1=$ always to $5=$ never. Higher sores indicated higher levels of reported adherence.
The original authors provided an approved version of the translated and validated MARS-5 instrument in Arabic.

\section{Procedure, sampling strategy, and sample size calculation}

This sample was selected using a multistage, stratified, sampling method. First, the clinics were selected on the basis of the ratio of $\mathrm{MOH}$ primary care clinics per health region. In Kuwait, the healthcare system is divided into five regional health authorities and primary health care is provided through 98 clinics distributed across the health regions proportionate to their population. A sample of $\sim 30 \%$ of all primary care polyclinics was selected. This sample represented 29 clinics, and their distribution per region was proportionate to the total number of clinics, as specified: eight in Capital, six in Al-Farwaniyah, six in Al-Ahmadi, five in Hawally, and four in Al-Jahra. The individual clinics were then conveniently selected in each health region.

Within each selected clinic, a systematic random sampling method was used to select patients who presented to the pharmacy to fill out their prescription following an appointment with their physician in chronic disease management polyclinics. The pharmacist on duty provided the patients a package including an informed consent form describing the research and asking for their participation as well as a six-page questionnaire. After signing the informed consent, patients were asked to fill out the questionnaire while at the polyclinic and hand it back to the pharmacist after it was completed.

The sample size was determined using the PS power and sample size calculator V.3.05. A total sample size of 774 individuals was required to determine a $10 \%$ difference in proportion between two groups; for example, male vs female with $80 \%$ power and at 5\% significance level. Assuming a response rate of $80 \%$, a total sample size of 930 was approached. The number of patients assigned per clinic was calculated on the basis of the percentage of clinics in a given health region; for example, there were $\sim 25 \%$ of the total number of primary care clinics in the Capital health region, and this region was assigned $25 \%$ of the study subjects who were distributed equally among the selected clinics in the Capital region.

\section{Statistical data analysis}

The SPSS version 22 was used for data management, descriptive analysis, and exploratory factor analysis (EFA). Structural equation modeling (SEM) was used as the main method of data analysis, and the AMOS 25.0 (AMOS IBM, 
USA) software was used for this purpose. The SEM allowed for simultaneous testing of the relationships between latent constructs (constructs that are composed of several measures, eg, beliefs, adherence in this research) and other measured constructs (eg, the background variables). Based on the BMQ-12, a theorized model on the relationship between beliefs about medications and adherence was developed and is presented in Figure 1.

Prior to examining various structural models among latent constructs, a preliminary screening of all the scales took place. Screening for missing data showed no missing values. Screening to assess internal consistency using Cronbach's alpha reliability coefficients, followed by EFA using the principal component method, was undertaken. Factors that were extracted from the EFA were then subjected to confirmatory factor analysis (CFA) to arrive at the measurement model; this measurement model was used as the basis for the SEM to test the relationships between the various variables. In addition to modeling chi-squared with degrees of freedom, we followed recommendations by Schreiber and reported the following goodness-of-fit measures: root mean square error of approximation (RMSEA), comparative fit index (CFI), and the standardized root mean square residual (SRMR). A model was determined to have acceptable fit if the CFI was greater than 0.95 , the RMSEA index was smaller than 0.06 , and the SRMR was less than or equal to $0.8 .{ }^{31}$ The final measurement model had a chi-squared value of 68.319 ( $\mathrm{df}=36, \mathrm{n}=783 ; p=0.001)$, with excellent goodness-of-fit values on all measures $(\mathrm{CFI}=0.981, \mathrm{RMSEA}=0.034$, and SRMR $=0.026)$.

\section{Screening of the scales}

Cronbach's alpha reliability estimates for each of five scales used in the study are presented in Table 1 . These were the three subscales for the BMQ-General (General-Overuse, General-Harm, and General-Benefit), SS-5, and MARS. Only MARS-5 and the BMQ-Harm subscale demonstrated acceptable reliability (alpha $>0.7$ ). To determine the dimensionality of the scales, all items were submitted to principal component EFA with varimax rotation. Six factors were identified with eigenvalues greater than 1.0 (Table 2). Here again, only items of the MARS-5 scales and the BMQ-Harm subscale loaded consistently in unique factors, minimally overlapping with other factors and having acceptable loading coefficients ( $>0.6$, except for one item). Items of the SS-5 scale were dichotomized into two factors - Factor 3 and Factor 6 - suggesting separate dimensions. Items of the BMQ-Overuse loaded into three different factors, whereas items of the BMQ-Benefit loaded into two separate ones with both subscales having low loading coefficients

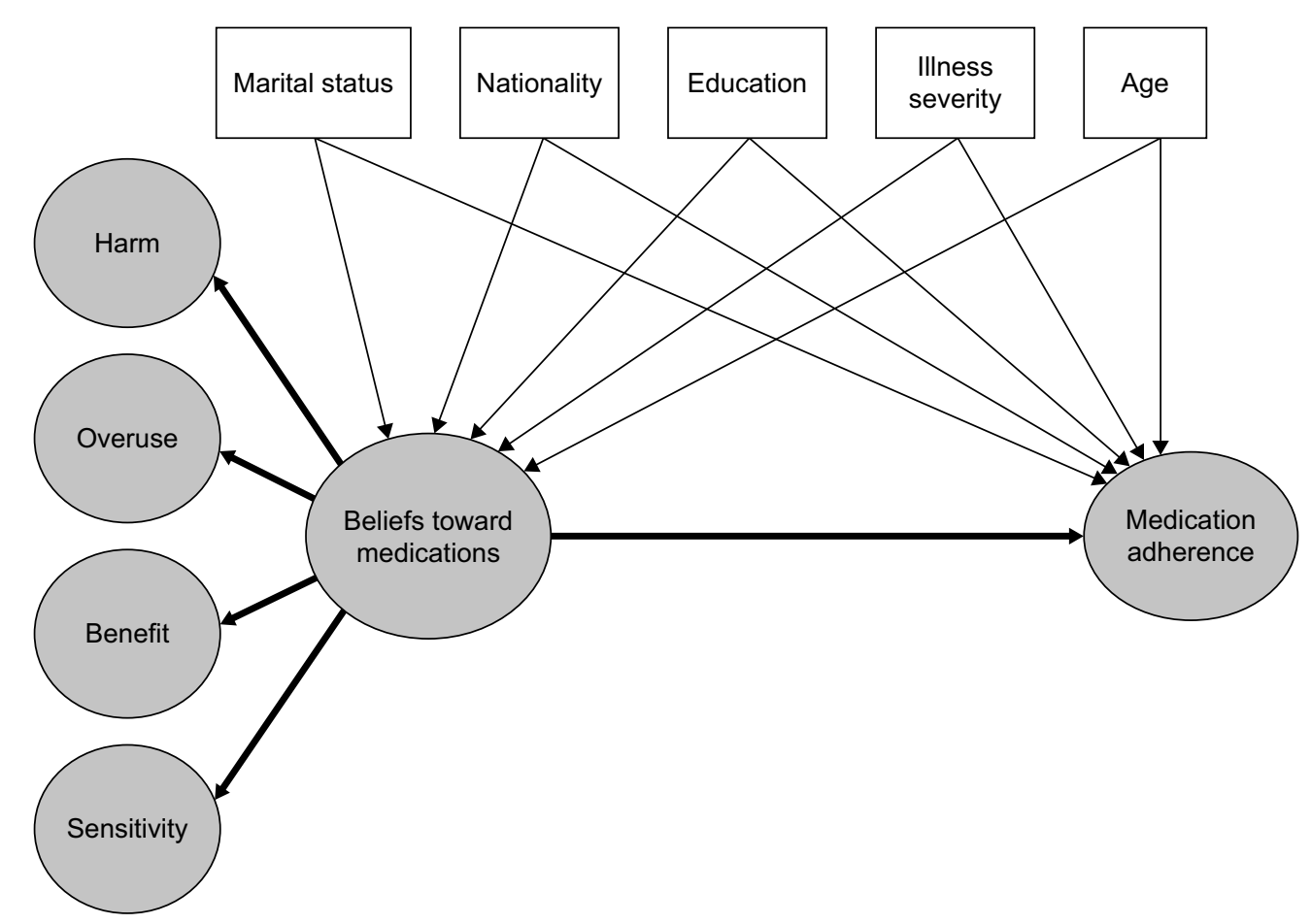

Figure I The theorized model of the relationships between beliefs about medications and medication adherence, controlling for patient background variables; hypothesized correlations are omitted from the figure for simplicity. 
Table I Descriptive statistics for the scales used, alpha reliability coefficients, and Cronbach's alpha when items were deleted

\begin{tabular}{|c|c|c|c|c|}
\hline Scales and items & Mean & SD & $\begin{array}{l}\text { Corrected item- } \\
\text { total correlation }\end{array}$ & $\begin{array}{l}\text { Cronbach's alpha } \\
\text { if item deleted }\end{array}$ \\
\hline MARS-5 (Cronbach's alpha $=0.822$ ) & 20.72 & 4.056 & & \\
\hline MAI: I forget to take my medicine & 3.67 & 1.188 & 0.588 & 0.797 \\
\hline MA2: I change the dose of my medicine & 4.36 & 0.990 & 0.610 & 0.788 \\
\hline MA3: I stop taking my medicine for a while & 4.10 & 1.107 & 0.657 & 0.773 \\
\hline MA4: I decide to miss out a dose of my medicine & 4.19 & $\mathrm{I} .028$ & 0.678 & 0.768 \\
\hline MA5: I take less of my medicine than instructed & 4.40 & 0.982 & 0.552 & 0.804 \\
\hline BMQ-Harm (Cronbach's alpha = 0.736) & 10.75 & 3.044 & & \\
\hline $\begin{array}{l}\text { BG2: people who take medicines should stop their treatment for a while every } \\
\text { now and again }\end{array}$ & 2.66 & 1.084 & 0.442 & 0.728 \\
\hline BG3: most medicines are addictive & 2.81 & 1.051 & 0.591 & 0.638 \\
\hline BG5: medicines do more harm than good & 2.58 & 0.950 & 0.549 & 0.665 \\
\hline BG6: all medicines are poisons & 2.70 & 0.985 & 0.537 & 0.671 \\
\hline BMQ-Overuse (Cronbach's alpha $=\mathbf{0 . 3 3 0})$ & 13.62 & 2.388 & & \\
\hline BGI: doctors use too many medicines & 3.13 & 1.169 & 0.231 & 0.189 \\
\hline BG4: natural remedies are safer than medicines & 3.47 & 1.042 & 0.171 & 0.271 \\
\hline BG7: doctors place too much trust on medicines & 3.72 & 0.803 & 0.086 & 0.350 \\
\hline BG8: if doctors had more time with patients they would prescribe fewer medicines & 3.30 & 1.092 & 0.197 & 0.238 \\
\hline BMQ-Benefit (Cronbach's alpha $=0.54 I)$ & 14.77 & 2.257 & & \\
\hline BG9: medicines help many people to live better lives & 3.93 & 0.822 & 0.406 & 0.405 \\
\hline BG I0: in the future medicines will be developed to cure most diseases & 3.93 & 0.798 & 0.318 & 0.478 \\
\hline BGII: in most cases the benefits of medicines outweigh the risks & 3.63 & 0.840 & 0.294 & 0.497 \\
\hline BG I2: medicines help many people to live longer & 3.28 & 1.005 & 0.306 & 0.497 \\
\hline SS (Cronbach's alpha $=0.566)$ & 14.96 & 2.837 & & \\
\hline SSI: my body is very sensitive to medicines & 2.88 & 1.057 & 0.416 & 0.451 \\
\hline SS2: my body overreacts to medicines & 3.56 & 0.855 & 0.094 & 0.623 \\
\hline SS3: I usually have stronger reactions to medicines than most people & 3.07 & 0.853 & 0.323 & 0.512 \\
\hline SS4: I have had a bad reaction to medicines in the past & 2.71 & 0.986 & 0.317 & 0.515 \\
\hline SS5: even very small amounts of medicines can upset my body & 2.75 & 0.927 & 0.495 & 0.408 \\
\hline
\end{tabular}

Note: The bold distinguishes statistics related to the total scale as opposed to statistics related to particular items.

Abbreviations: MARS, Medication Adherence Report Scale; BMQ, Beliefs about Medication Questionnaire; SS, sensitive soma.

(most were $<0.6$ ). This analysis provided evidence that there were at least three usable constructs with distinct dimensions in the data - namely, MARS, General-Harm, and a part of the SS-5.

\section{Measurement model}

We first carried out a CFA with 14 items; the five MARS items were allowed to load freely on one latent variable (ie, adherence), the four BMQ-Harm (ie, harm), and the three items from SS-5 (ie, sensitivity). As the analysis showed poor fit (fit indices did not meet the minimum), several CFAs were carried out until arriving at a good fit. Examination of modification indices did not result in improvement in model fit and, therefore, were not used to modify it. The final measurement model had a chi-squared value of $17.1(\mathrm{df}=11$, $\mathrm{n}=783 ; p=0.105)$ with excellent goodness-of-fit values on all measures $(\mathrm{CFI}=0.996$, RMSEA $=0.027$, and SRMR $=$ 0.022). As shown by the latent variable in the SEM model of Figure 2 (excluding background variables), this measurement model contained a secondary order latent construct, which resulted from combining the Harm and Sensitivity latent constructs (ie, named "negative attitude toward medicines"), and a first-order adherence latent construct, by separating the five items of the MARS into three dimensions: 1) MA1 (representing forgetfulness); 2) the combination of MA3 and MA4 (representing stopping/skipping behavior); and 3) the combination of MA2 and MA5 (representing dose-change behavior). With the above structure and arrangement of measures, it was feasible to arrive at a measurement model with good-fit indices, and with acceptable standardized regression weights (range $=0.63-0.87$ ). Cronbach's alpha reliability estimates associated with the final three constructs were 0.77, 0.64, and 0.62 for MARS, Harm, and the Sensitivity scales, respectively.

\section{Structural model}

The constructed SEM modeled the relationship between negative attitude toward medicines (a second-order latent construct) and adherence (first-order latent construct), whereas incorporating background demographics and illness 
Table 2 Standardized item ladings from exploratory (principal component) factor analysis resulting in six-factor solution

\begin{tabular}{|c|c|c|c|c|c|c|}
\hline \multirow[t]{2}{*}{ Scales and items } & \multicolumn{6}{|c|}{ Factors } \\
\hline & $\mathbf{I}$ & 2 & 3 & 4 & 5 & 6 \\
\hline MARS-5 & 0.713 & & & & & \\
\hline I forget to take my medicine & 0.748 & & & & & \\
\hline I change the dose of my medicine & 0.769 & & & & & \\
\hline I stop taking my medicine for a while & 0.807 & & & & & \\
\hline I decide to miss out a dose of my medicine & 0.704 & & & & & \\
\hline I take less of my medicine than instructed & 0.713 & & & & & \\
\hline \multicolumn{7}{|l|}{ BMQ-Harm } \\
\hline \multicolumn{7}{|l|}{ while every now and again } \\
\hline BG3: most medicines are addictive & & 0.747 & & & & \\
\hline BG5: medicines do more harm than good & & 0.618 & 0.345 & & & \\
\hline BG6: all medicines are poisons & & 0.649 & & & & \\
\hline \multicolumn{7}{|l|}{ BMQ-Overuse } \\
\hline BGI: doctors use too many medicines & & 0.538 & & & & \\
\hline BG4: natural remedies are safer than medicines & & 0.602 & & & -0.395 & \\
\hline BG7: doctors place too much trust on medicines & & & & 0.521 & 0.453 & \\
\hline BG8: if doctors had more time with patients they would prescribe & & & & 0.737 & & \\
\hline \multicolumn{7}{|l|}{ fewer medicines } \\
\hline \multicolumn{7}{|l|}{ BMQ-Benefit } \\
\hline BG9: medicines help many people to live better lives & & & & & 0.626 & \\
\hline BGI0: in the future medicines will be developed to cure most diseases & & & & 0.545 & & \\
\hline BGII: in most cases the benefits of medicines outweigh the risks & & & & 0.428 & & \\
\hline BG I2: medicines help many people to live longer & & & & & 0.794 & \\
\hline \multicolumn{7}{|l|}{ ss } \\
\hline SSI: my body is very sensitive to medicines & & & 0.787 & & & \\
\hline SS2: my body over-reacts to medicines & & & & & & 0.799 \\
\hline SS3: I usually have stronger reactions to medicines than most people & & & & & & 0.805 \\
\hline SS4: I have had a bad reaction to medicines in the past & & & 0.676 & & & \\
\hline SS5: even very small amounts of medicines can upset my body & & 0.333 & 0.673 & & & \\
\hline Cumulative \% variance explained after extraction & $14.1 \%$ & $26.2 \%$ & $35.1 \%$ & $42.7 \%$ & $49.8 \%$ & $56.6 \%$ \\
\hline
\end{tabular}

Notes: Table values are varimax-rotated factor loadings. Factor loadings $<0.3$ are not presented in the table. The bold is to emphasize that loading such items are acceptable to count together for a unique factor.

Abbreviations: MARS, Medication Adherence Report Scale; BMQ, Beliefs about Medication Questionnaire; SS, sensitive soma.

characteristics. An illness perception variable was created for each participant by combining the standardized score of comorbidity ( $z$-score) and the standardized score of number of medicines. Demographic variables that do not appear in the SEM (eg, gender) did not have statistically significant relationships with neither a negative attitude toward medicines nor with adherence; therefore, these are omitted from Figure 2.

\section{Results \\ Demographics}

Of the 1,150 questionnaires distributed to patients, a total of 783 questionnaires were collected, indicating a response rate of $68.1 \%$. The sociodemographic characteristics of the participants are presented in Table 3 and consisted of $56.7 \%$ male patients. Most patients were married (73.7\%) and approximately half were employed full time (57.9\%), with income less than 1,000 KD monthly (49.4\%). In terms of nationalities, approximately half were Kuwaiti nationals $(\mathrm{n}=366 ; 46.7 \%)$, followed by citizens of Egypt $(\mathrm{n}=182$; $23.2 \%)$, Syria $(n=54 ; 6.9 \%)$, Jordan $(n=33 ; 4.2 \%)$, India ( $n=29 ; 3.7 \%)$, Saudi Arabia $(n=19 ; 2.4 \%)$, Palestine $(n=16 ; 2.0 \%)$, Pakistan $(n=16 ; 2.0 \%)$, Iran $(n=16 ; 2.0 \%)$, and Lebanon $(\mathrm{n}=14 ; 1.8 \%)$. Individuals in the rest of the sample were categorized as either citizens of other Arab countries $(n=13 ; 1.7 \%)$, non-Arab countries $(n=17 ; 2.2 \%)$, or unidentified nationalities $(\mathrm{n}=8 ; 1.0 \%)$.

Patients were provided with a list of 18 health conditions related to four disease categories and asked to select all the conditions they experience. Large proportions of patients self-reported cardiovascular illnesses $(80.2 \%)$ and diabetes mellitus $(67.7 \%)$ and, to a lesser extent, respiratory diseases (24.3\%) or mood disorders (28.6\%). Participants reported a mean \pm SD of two comorbid disease categories $(2.0 \pm 0.9)$. A third of the patients (28.4\%) reported illnesses in one disease category; approximately half (44.1\%) had illnesses 


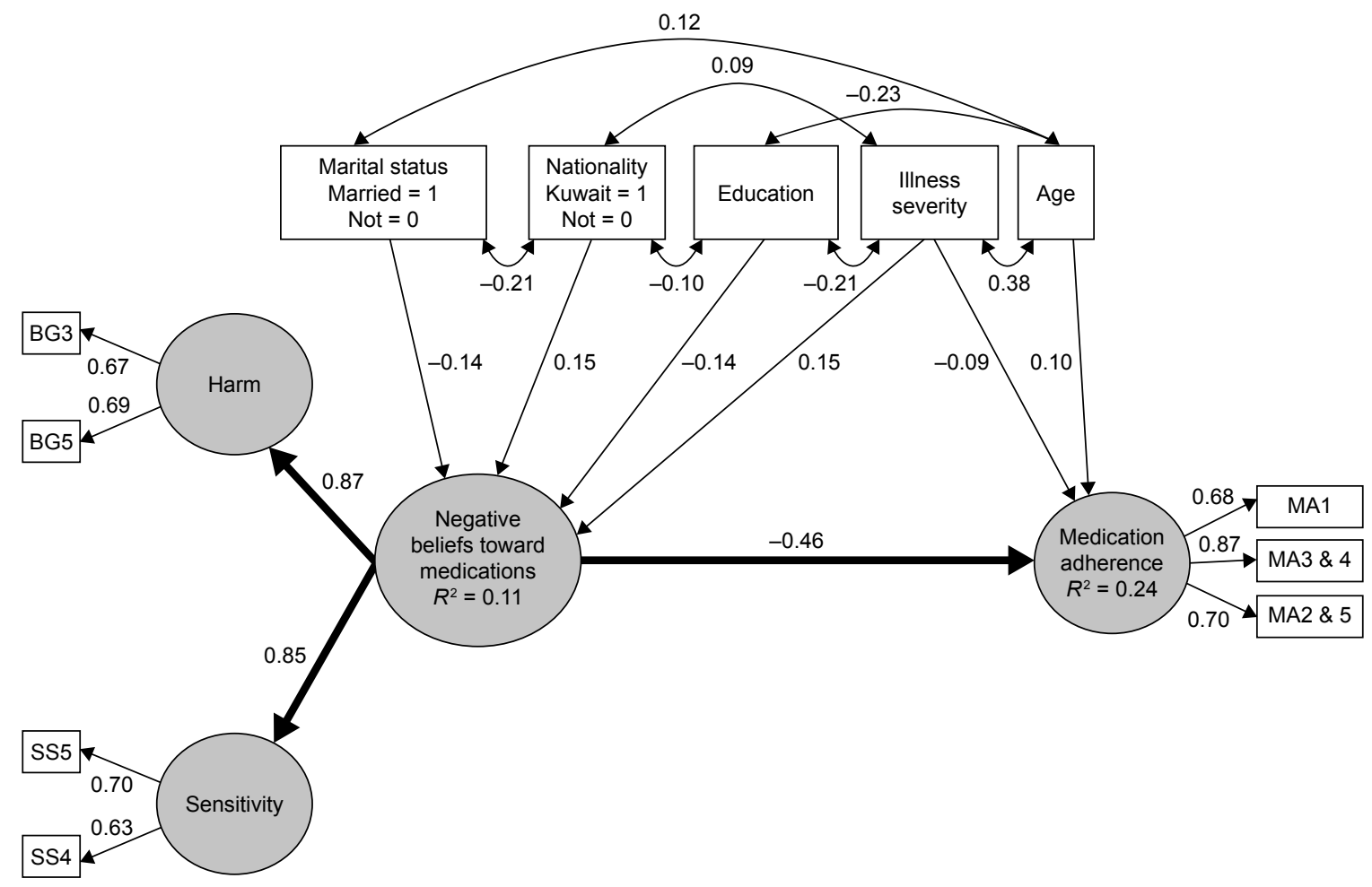

Figure 2 Structural equation model of adherence as a function of negative beliefs toward medications and background variables.

Notes: $\chi^{2}=68.319(\mathrm{df}=36, \mathrm{n}=783 ; p=0.001), \mathrm{CFI}=0.98 \mathrm{I}$, RMSEA $=0.034$, and SRMR $=0.026$. All paths are statistically significant at $p<0.05$. Paths representing effects of background variables are drawn in thinner lines. Illness severity = z-score of comorbidity + z-score of number of medications.

Abbreviations: BG, belief-general; SS, sensitive soma; MA, medication adherence; RMSEA, root mean square error of approximation; CFI, comparative fit index; SRMR, standardized root mean square residual.

in two diseases categories; and one fifth (20.9\%) reported three comorbid diseases. Very few (5.4\%) reported conditions in all four disease categories. Moreover, participants indicated taking an average of four prescription medicines to treat their illnesses (Table 4).

\section{Factors associated with medication adherence}

The results of the SEM on relationships between negative attitude and adherence to medication are shown in Figure 2. Indices used to test the model produced a chi-squared value of $68.3(\mathrm{df}=36, \mathrm{n}=783 ; p=0.001)$, with excellent goodnessof-fit values on all measures ( NFI $=0.96, \mathrm{CFI}=0.98$, and RMSEA $=0.034)$. The path coefficients depicted in Figure 2 were all statistically significant $(p<0.05)$. The standard regression coefficient (beta) of -0.46 indicated that negative beliefs toward medications have a significant negative impact on adherence to the treatment regimen.

Background factors that were associated with patients having negative beliefs toward medications included marital status (being unmarried; beta $=-0.14$ ), nationality (being Kuwaiti; beta $=0.15)$, higher illness severity (beta $=0.15$ ), and lower education (beta $=-0.14$ ). Further, younger age
$($ beta $=0.10)$ and higher illness severity $($ beta $=-0.9)$ were independently associated with decreased medication adherence (Figure 2). Gender and income were not statistically associated with negative beliefs toward medications or medication adherence. Of note, illness severity was significantly correlated with older age $(r=0.38)$, lower education level $(r=-0.21)$, and, to a lower extent, nationality (being Kuwaiti; $r=0.09$ ).

Overall, negative attitudes toward medication, young age, and higher illness severity explained $24 \%$ of the variance in medication adherence, whereas nationality, marital status, lower education level, and higher illness severity explained $11 \%$ of the negative attitudes toward medications.

\section{Discussion}

Overall, this study showed that negative beliefs toward medications have a significant negative impact and explained $24 \%$ of the variance of the adherence of chronically ill patients to their treatment regimen. Similar to our observation, others have reported that beliefs about medications were significant predictors of adherence and accounted for $19 \%-21 \%$ of the variance in adherence. ${ }^{4,12}$ Collectively, this suggests that although negative beliefs about medications are 
Table 3 Demographic characteristics $(N=783)$

\begin{tabular}{|c|c|c|}
\hline Characteristics & $\mathbf{n}$ & $\%$ \\
\hline \multicolumn{3}{|l|}{ Gender } \\
\hline Male & 444 & 56.7 \\
\hline Female & 339 & 43.3 \\
\hline \multicolumn{3}{|l|}{ Age, years } \\
\hline $18-39$ & 191 & 24.4 \\
\hline $40-49$ & 236 & 30.1 \\
\hline $50-59$ & 219 & 28.0 \\
\hline 60 or more & 137 & 17.5 \\
\hline \multicolumn{3}{|l|}{ Marital status } \\
\hline Single & 81 & 10.3 \\
\hline Married & 577 & 73.7 \\
\hline Divorced & 51 & 6.5 \\
\hline Widowed & 74 & 9.5 \\
\hline \multicolumn{3}{|l|}{ Nationality } \\
\hline Kuwaiti & 366 & 46.7 \\
\hline Non-Kuwaiti & 417 & 53.3 \\
\hline \multicolumn{3}{|l|}{ Monthly income } \\
\hline$<$ KD I,000 & 387 & 49.4 \\
\hline KD I,000-I,500 & 191 & 24.4 \\
\hline KD I,500-2,000 & 92 & 11.7 \\
\hline$\geq \mathrm{KD} 2,000$ & 105 & 13.4 \\
\hline Missing & 8 & 1.0 \\
\hline \multicolumn{3}{|l|}{ Education } \\
\hline Less than high school & 168 & 21.5 \\
\hline High school & 142 & 18.1 \\
\hline Some college & $|5|$ & 19.3 \\
\hline University & 248 & 31.7 \\
\hline Graduate degree & 74 & 9.5 \\
\hline \multicolumn{3}{|l|}{ Employment } \\
\hline Retired & 120 & 15.3 \\
\hline Unemployed & 140 & 17.9 \\
\hline Employed part time & 70 & 8.9 \\
\hline Employed full time & 453 & 57.9 \\
\hline \multicolumn{3}{|l|}{ Governorate } \\
\hline Capital & 200 & 25.5 \\
\hline Farwanya & 183 & 23.4 \\
\hline Alahmadi & 136 & 17.4 \\
\hline Hawalli & 153 & 19.5 \\
\hline Aljahra & III & 14.2 \\
\hline
\end{tabular}

Abbreviation: KD, Kuwaiti Dinars.

a significant predictor, other factors contribute to suboptimal adherence.

Our data showed that younger age and higher illness severity were significantly associated with decreased adherence. These findings are supported by reports among patients suffering from various illnesses. ${ }^{8,32,33}$ A meta-analysis looking at the relationship between illness severity and adherence showed that greater illness severity and the patient's awareness of the severity were associated with poorer adherence to medications, which supported our findings. ${ }^{13}$ However, a recent study conducted in Kuwait among patients with hypercholesterolemia showed that less severely ill younger patients were less adherent to their medicines as compared to
Table 4 Self-reported disease conditions and number of medications $(\mathrm{N}=783)$

\begin{tabular}{lll}
\hline Characteristics & $\mathbf{n}$ & $\%$ \\
\hline Disease categories & & \\
CVD & 628 & 80.2 \\
DM & 530 & 67.7 \\
Respiratory disease & 190 & 24.3 \\
Mood disorder & 224 & 28.6 \\
Comorbidity mean \pm SD (range) & $2.0 \pm 0.9(0-4)$ & \\
One disease category & 222 & 28.4 \\
Two disease categories & 345 & 44.1 \\
Three disease categories & 164 & 20.9 \\
Four disease categories & 42 & 5.4 \\
None & 10 & 1.3 \\
Medications mean \pm SD (range) & $4.0 \pm 2.6(I-18)$ & \\
One medication & 115 & 14.7 \\
Two medications & 129 & 16.5 \\
Three medications & 154 & 19.7 \\
Four medications & 118 & 15.1 \\
Five and six medications & 162 & 20.7 \\
Seven or more medications & 105 & 13.4 \\
\hline
\end{tabular}

Notes: aA "yes" on one or more of 18 listed conditions; II for CVD, two for DM, two respiratory diseases, and three for mood disorder (other options were: "no", "sometimes", and "I don't know"). bHad no "yes" on any of the 18 listed conditions. Abbreviations: CVDs, cardiovascular diseases; DM, diabetes mellitus.

older patients with several comorbid conditions. ${ }^{8}$ The authors suggested that more severely ill older patients were more attentive to their treatment regimen because they were more aware of their own mortality compared to younger patients. ${ }^{8,34}$ Furthermore, data showed that, compared with less adherent younger patients who were more likely to be newly diagnosed and less familiar with their illness and medications, ${ }^{32,35-37}$ older patients may be more adherent due to increased support with their treatment regimen, higher number of comorbid conditions, and better knowledge of their illnesses and their consequences if left untreated. ${ }^{34,36,38-40}$

There is mixed evidence on the impact of gender on medication adherence, with some reports showing that women tended to be less adherent and others finding no association between gender and adherence..$^{7,8,19,41-48}$ Similar to observations reported in studies among patients in the Middle East, adherence was not associated with gender in the present study. ${ }^{8,19}$

The current findings indicated that patients were more likely to have negative beliefs about medications if they had lower education level and higher illness severity and were Kuwaiti nationals. Similarly, nationality, education level, and perceived illness severity were identified as factors that influenced beliefs about medicines. ${ }^{12,26,49}$ The impact of nationality on beliefs about medications further suggested that cultural background may have a significant influence 
on patient's beliefs. ${ }^{22}$ Several studies have investigated personality traits such as pessimism and optimism and, interestingly, results consistently showed that Kuwaitis - compared to Americans or other Arab nationalities - were less optimistic and more pessimistic, meaning that they had a more negative view and outlook. ${ }^{50-52}$ Although we can only speculate, these observations support our findings by which being Kuwaiti was associated with more negative beliefs about medication.

One of the strengths of this study was that it capitalized on the methodological advantages of SEM, which increased the ability to find relationships that were not possible to detect using regression analysis. Adherence and negative beliefs were conceptualized as latent constructs that were formed by combining the measured variables. Using several measures for one construct improved the reliability to estimate the magnitude of the calculated relationship, as opposed to the use of a single total for each construct. Moreover, the SEM allowed the estimation of relationships between negative beliefs and adherence while controlling for the effects of multiple background variables at the same time.

Another benefit of using SEM was that the analysis suggested new ways for conceptualizing negative beliefs about medicine and medication adherence. Seeking a measurement model with good-fit indices lead to specifications and modifications that resulted in combining BMQ-Harm and SS-5 into the new latent construct - negative beliefs. It made theoretical sense that one's perception that medicines to do more harm than good was also related to one's perception that his/her body was vulnerable to medicines. This was not feasible in previous research that used traditional regression analysis. Similarly, the analyses lead to a medication adherence latent construct that was composed of at least three dimensions: forgetfulness, skipping doses, and changing regimens. Although the EFA extracted all the five MARS items into one factor, subsequent analysis by CFA during the building of the measurement model did not result in acceptable standardized regression weights for the five measures into the adherence construct. A measurement model with good-fit indices and acceptable loading coefficients was only achieved when the five items were reoriented into three: 1) MA1, relating to forgetfulness; 2) MA3 and MA4, relating to skipping doses; and 3) MA2 and MA5, relating to changing regimens. This finding warrants further studies to investigate dimensions of medication nonadherence beyond the customary two: intentional and unintentional.

A limitation of this study was the poor reliability found among the items of the instruments used in the study - namely, the Cronbach's alphas of $0.33,0.54$, and 0.57 for BMQ-Overuse, BMQ-Benefit, and the SS-5 scales, respectively. Furthermore, exploratory factor analysis solution did not result in the expected number of factors; with low loading coefficients and items belonging to a subscale loading into more than one factor. Similar observations were reported by the authors who translated and validated the BMQ in Arabic among chronically ill patients, with acceptable internal reliability for the total instrument (alpha 0.71 ) but poor reliability for the individual subscales (alpha $0.3-0.65) .{ }^{20}$ These results are in contrast to several previous reports where the internal reliability for MARS-5, BMQ-12, and SS-5 instruments ranged from 0.66 to $0.89 .{ }^{12,21-25}$ However, and similar to our findings, the internal reliability was improved when items of the BMQ-12 instrument were grouped differently. ${ }^{22}$ Furthermore, our results indicated good reliability with the MARS-5 and BMQ-Harm (alpha 0.822 and 0.736, respectively), suggesting the low reliability may reside in specific statements of some subscales, but not in all.

Most studies reporting good internal reliability were conducted using the original English language instruments in European, American, or New Zealand populations. When translated and administered in Arabic, the internal reliability decreased, suggesting a need for cultural adaptation of these measures. Research needs to further explore cultural differences in beliefs related to medications - and to health, in general - and develop measures that produce more reliable and valid instruments in the Arabic language. In light of the accumulating evidence suggesting that medications beliefs explain a significant but partial proportion of adherence behavior, future research needs to include other potential predictors. For example, it has been shown consistently that adherence to antiretroviral medications was predictable by the concept of self-efficacy ${ }^{53,54}$ - that is, the confidence in one's ability to adhere to treatment despite difficulties encountered, such as side effects, interference with daily routine, or emotional state. Therefore, a broader inclusion of various factors shown by previous research to impact medication adherence should lead to better model conceptualization with more power for prediction.

Collectively, the growing body of data from examining factors that predict medication adherence showed that it is a multifaceted and complex issue that requires healthcare professionals to explore, identify, and create tools and strategies to overcome these barriers. Several reports showed that when pharmacists participated in educating and counseling patients about the importance of adherence, explaining the side effects of medications, reviewing regimens, providing written instructions, monitoring drugs, and following up 
drug reactions, their intervention had a positive impact on medication adherence. ${ }^{55-57}$ Our study showed that negative beliefs about medications from chronically ill patients being followed-up in the primary care setting contributed to lower adherence. This observation mandates that healthcare providers intervene by educating patients to mitigate the impact of these negative beliefs. In fact, patients who were knowledgeable about their illness and related consequences if not treated, their medications, and therapeutic goals were more likely to be adherent to their treatment regimen., ${ }^{7,11,19}$ Although recent data from Kuwait showed that the most commonly offered services by pharmacists in hospital settings were healthcare education and drug information to patients, ${ }^{58}$ it remains to be determined if this is also the case in primary settings and highlights an opportunity for improving and expanding the pharmacists' role in primary care centers. In Kuwait, data showed that although physicians spend minimal time counseling patients on their medications following any intervention on treatment regimen, they strongly believed that involving pharmacists in patient counseling would have a positive impact on medication adherence. ${ }^{58}$ Collectively, these observations suggest a pivotal role for pharmacists in improving medication adherence. Optimizing patient education and counseling is part of the solution and there is a need to explore other parameters that may affect adherence, such as religious beliefs, social customs, and traditions, or factors related to dosing schedule, complexity of regimen, and patient's knowledge of therapeutic targets. ${ }^{6,7}$

\section{Conclusion}

Overall, we found that negative beliefs toward medications among a multicultural group of chronically ill patients in Kuwait significantly but partially explained adherence to their treatment regimen. There is a need to better understand factors, other than negative beliefs, that are critical determinants of adherence to medications and to develop relevant strategies to mitigate their impact.

\section{Acknowledgments}

The authors gratefully acknowledge the contribution of Prof Pierre Moreau, Dean of the Faculty of Pharmacy, Kuwait University, for his thorough review and advice with regard to the manuscript. This study was funded by the Kuwait University Research Sector (grant no PT02/16).

\section{Disclosure}

The authors report no conflicts of interest in this work.

\section{References}

1. WHO. Adherence to Long-Term Therapies: Evidence for Action. Geneva: World Health Organization; 2003.

2. Osterberg L, Blaschke T. Adherence to medication. NEngl JMed. 2005; 353(5):487-497.

3. Vermeire E, Hearnshaw H, Van Royen P, Denekens J. Patient adherence to treatment: three decades of research. A comprehensive review. J Clin Pharm Ther. 2001;26(5):331-342.

4. Horne R, Weinman J. Patients' beliefs about prescribed medicines and their role in adherence to treatment in chronic physical illness. J Psychosom Res. 1999;47(6):555-567.

5. Al-Qasem A, Smith F, Clifford S. Adherence to medication among chronic patients in Middle Eastern countries: review of studies. East Mediterr Health J. 2011;17(4):356-363.

6. Jeragh-Alhaddad FB, Waheedi M, Barber ND, Brock TP. Barriers to medication taking among Kuwaiti patients with type 2 diabetes: a qualitative study. Patient Prefer Adherence. 2015;9:1491-1503.

7. Waheedi M, Awad A, Hatoum HT, Enlund H. The relationship between patients' knowledge of diabetes therapeutic goals and self-management behaviour, including adherence. Int J Clin Pharm. 2017;39(1):45-51.

8. Al-Foraih M, Somerset S. Factors affecting adherence to statins in hypercholesterolemic Kuwaiti patients: a cross-sectional study. Med Princ Pract. 2017;26(1):35-40.

9. Al-Saffar N, Deshmuckh A, Eid S, Carter P. Health beliefs and drug compliance of depressed patients in Kuwait. J Soc Adm Pharm. 2003; 20(4):142-150.

10. Fido AA, Husseini AM. Noncompliance with treatment among psychiatric patients in Kuwait. Med Princ Pract. 1998;7(1):28-32.

11. Broadbent E, Donkin L, Stroh JC. Illness and treatment perceptions are associated with adherence to medications, diet, and exercise in diabetic patients. Diabetes Care. 2011;34(2):338-340.

12. Rajpura JR, Nayak R. Role of illness perceptions and medication beliefs on medication compliance of elderly hypertensive cohorts. J Pharm Pract. 2014;27(1):19-24.

13. DiMatteo MR, Haskard KB, Williams SL. Health beliefs, disease severity, and patient adherence: a meta-analysis. Med Care. 2007;45(6): 521-528.

14. Rajpura J, Nayak R. Medication adherence in a sample of elderly suffering from hypertension: evaluating the influence of illness perceptions, treatment beliefs, and illness burden. J Manag Care Pharm. 2014;20(1):58-65.

15. Bailey CJ, Kodack M. Patient adherence to medication requirements for therapy of type 2 diabetes. Int J Clin Pract. 2011;65(3):314-322.

16. Chia LR, Schlenk EA, Dunbar-Jacob J. Effect of personal and cultural beliefs on medication adherence in the elderly. Drugs Aging. 2006;23(3):191-202.

17. Crowe M, Wilson L, Inder M. Patients' reports of the factors influencing medication adherence in bipolar disorder - an integrative review of the literature. Int J Nurs Stud. 2011;48(7):894-903.

18. Salt E, Frazier SK. Adherence to disease-modifying antirheumatic drugs in patients with rheumatoid arthritis: a narrative review of the literature. Orthop Nurs. 2010;29(4):260-275.

19. Awwad O, Akour A, Al-Muhaissen S, Morisky D. The influence of patients' knowledge on adherence to their chronic medications: a crosssectional study in Jordan. Int J Clin Pharm. 2015;37(3):504-510.

20. Alhalaiqa F, Masa'Deh R, Batiha AM, Deane K. Validity of Arabic version of beliefs about medication questionnaire. Clin Nurs Res. 2015; 24(5):539-555.

21. Horne R, Faasse K, Cooper V, et al. The perceived sensitivity to medicines (PSM) scale: an evaluation of validity and reliability. Br J Health Psychol. 2013;18(1):18-30.

22. Horne R, Graupner L, Frost S, Weinman J, Wright SM, Hankins M. Medicine in a multi-cultural society: the effect of cultural background on beliefs about medications. Soc Sci Med. 2004;59(6):1307-1313. 
23. Horne R, Weinman J, Hankins M. The beliefs about medicines questionnaire: the development and evaluation of a new method for assessing the cognitive representation of medication. Psychol Health. 1999; 14(1):1-24.

24. Menckeberg TT, Bouvy ML, Bracke M, et al. Beliefs about medicines predict refill adherence to inhaled corticosteroids. J Psychosom Res. 2008;64(1):47-54.

25. Tommelein E, Mehuys E, Van Tongelen I, Brusselle G, Boussery K. Accuracy of the Medication Adherence Report Scale (MARS-5) as a quantitative measure of adherence to inhalation medication in patients with COPD. Ann Pharmacother. 2014;48(5):589-595.

26. Chapman SC, Horne R, Chater A, Hukins D, Smithson WH. Patients' perspectives on antiepileptic medication: relationships between beliefs about medicines and adherence among patients with epilepsy in UK primary care. Epilepsy Behav. 2014;31:312-320.

27. Ramström H, Afandi S, Elofsson K, Petersson S. Differences in beliefs between patients and pharmaceutical specialists regarding medications. Patient Educ Couns. 2006;62(2):244-249.

28. Horne R, Petrie K, Davis C, Diefenbach M, Leventhal H, Leventhal E. The Sensitive Soma Assessment Scale (SSAS): a new measure for assessing perceptions of personal sensitivity to medicines. Paper presented at: 8th International Congress of Behavioural Medicine (ICBM); August 25-28, 2004; Mainz.

29. Trachtenberg FL, Mednick L, Kwiatkowski JL, et al; Thalassemia Clinical Research Network. Beliefs about chelation among thalassemia patients. Health Qual Life Outcomes. 2012;10:148.

30. Horne R, Weinman J. Self-regulation and self-management in asthma: exploring the role of illness perceptions and treatment beliefs in explaining non-adherence to preventer medication. Psychol Health. 2002;17(1):17-32.

31. Schreiber JB. Update to core reporting practices in structural equation modeling. Res Social Adm Pharm. 2017;13(3):634-643.

32. Krueger K, Botermann L, Schorr SG, Griese-Mammen N, Laufs U, Schulz M. Age-related medication adherence in patients with chronic heart failure: a systematic literature review. Int J Cardiol. 2015;184: 728-735.

33. Davies MJ, Gagliardino JJ, Gray LJ, Khunti K, Mohan V, Hughes R. Real-world factors affecting adherence to insulin therapy in patients with Type 1 or Type 2 diabetes mellitus: a systematic review. Diabet Med. 2013;30(5):512-524.

34. Latry P, Molimard M, Dedieu B, Couffinhal T, Bégaud B, Martin-Latry K. Adherence with statins in a real-life setting is better when associated cardiovascular risk factors increase: a cohort study. BMC Cardiovasc Disord. 2011;11:46.

35. Fischer MA, Stedman MR, Lii J, et al. Primary medication nonadherence: analysis of 195,930 electronic prescriptions. J Gen Intern Med. 2010;25(4):284-290.

36. van der Wal MH, Jaarsma T, Moser DK, Veeger NJ, van Gilst WH, van Veldhuisen DJ. Compliance in heart failure patients: the importance of knowledge and beliefs. Eur Heart J. 2006;27(4):434-440.

37. Wroth TH, Pathman DE. Primary medication adherence in a rural population: the role of the patient-physician relationship and satisfaction with care. J Am Board Fam Med. 2006;19(5):478-486.

38. Cohen MJ, Shaykevich S, Cawthon C, Kripalani S, Paasche-Orlow MK, Schnipper JL. Predictors of medication adherence postdischarge: the impact of patient age, insurance status, and prior adherence. $J$ Hosp Med. 2012;7(6):470-475.

39. Huang LH. Medication-taking behavior of the elderly. Kaohsiung $J$ Med Sci. 1996;12(7):423-433.

40. Monane M, Bohn RL, Gurwitz JH, Glynn RJ, Levin R, Avorn J. Compliance with antihypertensive therapy among elderly Medicaid enrollees: the roles of age, gender, and race. Am J Public Health. 1996;86(12): 1805-1808.
41. Carpenter DM, Hogan SL, Devellis RF. Predictors of medication nonadherence for vasculitis patients. Clin Rheumatol. 2013;32(5): 649-657.

42. Crawshaw J, Auyeung V, Norton S, Weinman J. Identifying psychosocial predictors of medication non-adherence following acute coronary syndrome: a systematic review and meta-analysis. J Psychosom Res. 2016;90:10-32.

43. De las Cuevas C, Peñate W, Sanz EJ. Risk factors for non-adherence to antidepressant treatment in patients with mood disorders. Eur J Clin Pharmacol. 2014;70(1):89-98.

44. Grigoryan L, Pavlik VN, Hyman DJ. Predictors of antihypertensive medication adherence in two urban health-care systems. Am J Hypertens. 2012;25(7):735-738.

45. Katz LL, Anderson BJ, McKay SV, et al; TODAY Study Group. Correlates of medication adherence in the TODAY cohort of youth with type 2 diabetes. Diabetes Care. 2016;39(11):1956-1962.

46. Khanna R, Pace PF, Mahabaleshwarkar R, Basak RS, Datar M, Banahan BF. Medication adherence among recipients with chronic diseases enrolled in a state Medicaid program. Popul Health Manag. 2012;15(5):253-260.

47. Lachaine J, Yen L, Beauchemin C, Hodgkins P. Medication adherence and persistence in the treatment of Canadian ulcerative colitis patients: analyses with the RAMQ database. BMC Gastroenterol. 2013;13:23.

48. Mosleh SM, Darawad M. Patients' adherence to healthy behavior in coronary heart disease: risk factor management among Jordanian patients. J Cardiovasc Nurs. 2015;30(6):471-478.

49. Mårdby AC, Akerlind I, Jörgensen T. Beliefs about medicines and self-reported adherence among pharmacy clients. Patient Educ Couns. 2007;69(1-3):158-164.

50. Abdel-Khalek A, Lester D. Optimism and pessimism in Kuwaiti and American college Students. Int J Soc Psychiatry. 2006;52(2): $110-126$.

51. Alansari BM. Relationship between depression and anxiety among undergraduate students in eighteen Arab countries: a cross-cultural study. Soc Behav Personal. 2005;33(5):503-512.

52. Alansari BM, Kazem AM. Optimism and pessimism in Kuwaiti and Omani undergraduates. Soc Behav Personal. 2008;36(4):503-518.

53. Johnson MO, Catz SL, Remien RH, et al; NIMH Healthy Living Project Team. Theory-guided, empirically supported avenues for intervention on HIV medication nonadherence: findings from the Healthy Living Project. AIDS Patient Care STDS. 2003;17(12):645-656.

54. Wolf MS, Davis TC, Osborn CY, Skripkauskas S, Bennett CL, Makoul G. Literacy, self-efficacy, and HIV medication adherence. Patient Educ Couns. 2007;65(2):253-260.

55. Al-Jumah KA, Hassali MA, Al-Zaagi I. Adaptation and validation of a questionnaire assessing patient satisfaction with pharmacy services in general hospitals. Patient Prefer Adherence. 2014;8:371-375.

56. Haynes RB, Ackloo E, Sahota N, McDonald HP, Yao X. Interventions for enhancing medication adherence. Cochrane Database Syst Rev. 2008;(2):CD000011.

57. Viswanathan M, Golin CE, Jones CD, et al. Interventions to improve adherence to self-administered medications for chronic diseases in the United States: a systematic review. Ann Intern Med. 2012;157(11): 785-795.

58. Lemay J, Waheedi M, Al-Taweel D, Bayoud T, Moreau P. Clinical pharmacy in Kuwait: services provided, perceptions and barriers. Saudi Pharm J. 2018;26(4):481-486. 


\section{Publish your work in this journal}

Patient Preference and Adherence is an international, peer-reviewed, open access journal that focuses on the growing importance of patient preference and adherence throughout the therapeutic continuum. Patient satisfaction, acceptability, quality of life, compliance, persistence and their role in developing new therapeutic modalities and compounds to optimize

clinical outcomes for existing disease states are major areas of interest for the journal. This journal has been accepted for indexing on PubMed Central. The manuscript management system is completely online and includes a very quick and fair peer-review system, which is all easy to use. Visit http://www. dovepress.com/testimonials.php to read real quotes from published authors.

Submit your manuscript here: http://www.dovepress.com/patient-preference-and-adherence-journal 